\title{
Influence of Body Height on Oral and Pharyngeal Transit Time of a Liquid Bolus in Healthy Volunteers
}

\author{
Marcia R.K. Bernardi Regueiro ${ }^{\mathrm{a}}$, Luana Casari Parreira ${ }^{\mathrm{a}}$, Weslania Viviane Nascimento ${ }^{\mathrm{b}}$, \\ Roberto Oliveira Dantas, c, d
}

\begin{abstract}
Background: Swallowing duration may be influenced by several factors. The effect of body height on oral-pharyngeal bolus transit has not been clearly elucidated. The hypothesis of this investigation was that height has influence on oral-pharyngeal transit time of a liquid bolus.

Methods: Videofluoroscopic assessment of swallowing was performed on 40 healthy volunteers: 20 "tall" (171 cm to $207 \mathrm{~cm})$ and 20 "short" (152 cm to $170 \mathrm{~cm})$ subjects, 10 men and 10 women in each group. Each subject performed three swallows of $10 \mathrm{~mL}$ of liquid barium bolus. The following parameters were measured: oral transit time (OTT): time from the beginning of tongue tip movement at incisors to arrival of the bolus tail at the fauces; pharyngeal transit time (PTT): time between the arrival of the bolus tail at fauces and complete passage of the bolus tail through the upper esophageal sphincter (UES); pharyngeal clearance (PC): time between the arrival of the bolus head at fauces to complete passage of the bolus tail through the UES; UES opening (UESO): time between the arrival of the bolus head at the UES to complete passage of the bolus tail through the UES; duration of hyoid movement (HM): time interval between the onset and the end of hyoid movement; oral-pharyngeal transit time (OPTT): time from the beginning of tongue tip movement at incisors until complete passage of the bolus tail through the UES. The statistical analysis was done by a linear model with mixed effects. Correlation between height and swallowing events duration was assessed by Spearman's correlation coefficient (r).
\end{abstract}

Results: In women OTT, PC, HM and OPTT were longer in tall than in short subjects, what was not seen in men. In women there was a positive correlation between OTT, PTT and OPTT and height. Men (mean height: $177 \mathrm{~cm}$ ) had longer PTT and PC than women (mean

Manuscript submitted June 27, 2018, accepted July 26, 2018

aDepartment of Ophthalmology, Otorhinolaryngology, Head and Neck Surgery, Ribeirao Preto Medical School, University of Sao Paulo, Ribeirao Preto SP, Brazil

${ }^{\mathrm{b}}$ Gastrointestinal Physiology Laboratory, Department of Surgery, Hospital of Mataro, Universitat Autonoma de Barcelona, Spain

'Department of Medicine, Ribeirao Preto Medical School, University of Sao Paulo, Ribeirao Preto SP, Brazil

${ }^{\mathrm{d} C o r r e s p o n d i n g ~ A u t h o r: ~ R o b e r t o ~ O l i v e i r a ~ D a n t a s, ~ R i b e i r a o ~ P r e t o ~ M e d i c a l ~}$ School, University of Sao Paulo, Av. Bandeirantes 3900, Ribeirao Preto SP, Brazil. Email: rodantas@fmrp.usp.br

doi: https://doi.org/10.14740/gr1063w height: $166 \mathrm{~cm})$.

Conclusions: In women, oral and pharyngeal transit time of a $10 \mathrm{~mL}$ liquid bolus were influenced by height and was longer in taller subjects.

Keywords: Deglutition; Swallowing; Dysphagia; Body height; Swallowing physiology

\section{Introduction}

Coordinated actions of muscles and nerves in oral, pharyngeal and esophageal phases are required for the safety and efficiency of swallowing [1]. Impairment of spatiotemporal coordination of the movements of oral and pharyngeal structures may cause abnormal swallowing [2].

Factors that may influence the swallowing include neurologic diseases [1,3], head and neck cancer and surgeries [3], upper gastrointestinal diseases [4-7], pulmonary disease [8,9] and the volume and consistency of swallowed bolus [10-14].

Some studies have demonstrated that sex may have an influence on the swallowing pattern, with differences between men and women in oral-pharyngeal transit [13, 15-19]. Other studies, however, did not find such differences [11, 14, 20]. Compared to shorter individuals, taller individuals have greater superior hyoid displacement [21] and other anatomic and functional differences that may affect swallowing time [22]. These data raised the possibility that differences in swallowing time between men and women may be attributed to differences in height rather than sex itself. Knowledge about the factors that influence the physiology of swallowing is important for the diagnosis and treatment of patients with swallowing impairment and consequent dysphagia.

In women, the pharyngeal air column is surrounded by smaller structures than in men, although no differences in linear measurements of the pharyngeal air column were found between the sexes [23]. Measurements of the pharyngeal cross-sectional area performed in the sitting position revealed greater values in men than in women though [24]. The possibility that these differences are associated with difference in body height was not evaluated.

Height affects the volume of larynx and hypopharynx [22]. Therefore, there may be a possible effect of height on the 
duration of swallowing events. The hypothesis of this investigation was that taller subjects have longer oral and pharyngeal bolus transit duration than shorter individuals, which may be consequent to the distance traveled by the bolus from mouth to the esophagus. If this hypothesis is true, assessment of timing of swallowing events should take into consideration the height of the individual.

Our objective in this investigation was to evaluate the influence of body height on oral-pharyngeal transit time of a liquid bolus in healthy men and women.

\section{Materials and Methods}

\section{Subjects}

Videofluoroscopic assessment of swallowing was performed on 40 healthy individuals, 20 men and 20 women aged 20 to 50 years. Details about the age, height, weight and body mass index of the volunteers were previously published [25]. Subjects were divided into "tall" and "short" groups, based on the mean height of the Brazilian population, i.e., $172 \mathrm{~cm}$ for men and $161 \mathrm{~cm}$ for women (Brazilian Institute of Geography and Statistics, 2009). Tall group (mean age: 27.8 years) was composed of 20 individuals whose height was greater than the population mean: 10 men with $180 \mathrm{~cm}$ to $207 \mathrm{~cm}$ of height and 10 women with $171 \mathrm{~cm}$ to $179 \mathrm{~cm}$ of height (mean of $181 \mathrm{~cm}$ ). The short group (mean age: 35.2 years) was composed of individuals whose height was below the population mean: 10 men with $161 \mathrm{~cm}$ to $170 \mathrm{~cm}$ of height and 10 women with $152 \mathrm{~cm}$ to $159 \mathrm{~cm}$ of height (mean of $162 \mathrm{~cm}$ ). No participant had swallowing difficulties for any food consistencies; no one took any medication, or had a history of surgery or digestive, neurologic or endocrine diseases. The study was approved by the Human Research Ethics Committee of the Ribeirao Preto University Hospital, IRB HCRP $n^{\circ}$ 1954/2010. Written informed consent was obtained from each participant and the anonymity of each volunteer was preserved.

\section{Videofluoroscopy}

Videofluoroscopy studies were performed using the Arcomax angiography system (model BV 300, Phillips, Veenpluis, The Netherlands). Images were recorded at 30 frames per second, and the maximum duration of the radiation exposure was 60 s. The examination was performed in the lateral position with the men and women seated on a chair, looking straight ahead, without moving their head during swallows. Non-cued swallows of $10 \mathrm{~mL}$ of liquid bolus were evaluated in triplicate. The liquid bolus was prepared with $30 \mathrm{~mL}$ of liquid barium sulfate (Bariogel ${ }^{\circledR}$ 100\%, Laboratorio Cristalia, Itapira SP, Brazil) diluted in $30 \mathrm{~mL}$ of water, and given to the individual using a plastic glass. Subjects leaned their heads back to receive the bolus in the mouth, and returned to rest position before swallowing. Bolus preparation was classified as level 1 (slightly thick) in the IDDSI flow test proposed by the International Dysphagia Diet Standardisation Initiative (IDDSI) [26].

\section{Measurements}

The following time parameters were assessed: 1) Onset of the propulsive movement of the tongue tip at the maxillary incisors; 2) Arrival of the bolus head at the fauces; 3) Arrival of the bolus tail at the fauces; 4) Onset and end of hyoid movement; 5) Bolus head enters the upper esophageal sphincter (UES); 6) Bolus tail completely passes through the UES.

The duration of the transit and movements during swallowing was measured as follows: 1) Oral transit time (OTT): time from the beginning of tongue tip movement at incisors to arrival of the bolus tail at the fauces; 2) Pharyngeal transit time (PTT): time between the arrival of the bolus tail at fauces to complete passage of the bolus tail through the UES; 3) Pharyngeal clearance (PC): time between the arrival of the bolus head at fauces to complete passage of the bolus tail through the UES; 4) UES opening (UESO): time between the arrival of the bolus head at the UES to complete passage of the bolus tail through the UES; 5) Duration of hyoid movement (HM): time between the onset and the end of hyoid movement; 6) Oral-pharyngeal transit time (OPTT): time from the beginning of tongue tip movement at incisors until complete passage of the bolus tail through the UES.

\section{Statistical analyses}

Statistical analysis was performed by ProEstat Estatistics and Research (Ribeirao Preto SP, Brazil). A linear model with mixed effects (random and fixed effects) [27] was performed, considering subjects' height as fixed effects, and subjects' repeated measures as random effect. The analysis was corrected by height and sex effects. Correlation between height and swallowing events duration was assessed by Spearman's correlation coefficient (r). The results are described as mean and $95 \%$ confidence interval $(95 \% \mathrm{CI})$, in milliseconds $(\mathrm{ms})$. The differences were considered significant when $\mathrm{P} \leq 0.05$.

\section{Results}

There was no difference in swallowing duration between tall and short individuals (Table 1). However, when the results were analyzed by sex we found that in men $(n=20$, mean height: $177 \mathrm{~cm}$ ) height had influence only on OTT, with was longer in short subjects (Table 2); whereas in women $(n=20$, mean height: $166 \mathrm{~cm}$ ) OTT, PC, HM and OPTT were longer in taller subjects (Table 3). Both PTT (men: $368 \mathrm{~ms}, 95 \% \mathrm{CI}$ : 314 - $422 \mathrm{~ms}$; women: $238 \mathrm{~ms}, 95 \% \mathrm{CI}: 219$ - $257 \mathrm{~ms}$ ) and PC (men: $621 \mathrm{~ms}, 95 \%$ CI: 556 - 687; women: $465 \mathrm{~ms}$; 95\% CI: 433 - 496) were longer in men than in women (Fig. 1, P $=0.02$ ), which also means that the group of individuals with higher mean height had longer PTT and PC than those with lower mean height.

Considering all volunteers $(n=40)$ there was a positive correlation between height and PTT $(r=0.40, \mathrm{P}=0.01$, Table 4). In men there was no correlation of height with swallowing transit time, but in women there was a positive correlation of 
Table 1. Oral and Pharyngeal Bolus Transit Duration (Milliseconds) in Shorter Men and Women (Mean Height: $1.62 \mathrm{~m}, \mathrm{~N}=$ 20) and Taller Men and Women (Mean Height: $1.81 \mathrm{~m}, \mathrm{~N}=20$ ), After Swallowing of $10 \mathrm{~mL}$ Liquid Barium Bolus

\begin{tabular}{lllllll} 
& \multicolumn{2}{c}{ Shorter } & & \multicolumn{3}{c}{ Taller } \\
\cline { 2 - 3 } \cline { 6 - 7 } & Mean & $\mathbf{9 5 \%}$ CI & & Mean & $\mathbf{9 5 \%}$ CI & P value \\
\hline OTT & 716 & $641-790$ & & 857 & $730-984$ & 0.62 \\
PTT & 276 & $249-304$ & & 329 & $275-385$ & 0.09 \\
PC & 522 & $475-569$ & & 564 & $502-626$ & 0.06 \\
UESO & 345 & $321-370$ & & 363 & $332-393$ & 0.29 \\
HM & 853 & $751-955$ & 902 & $820-985$ & 0.23 \\
OPTT & 1,024 & $921-1,127$ & 1,169 & $1,038-1,301$ & 0.38 \\
\hline
\end{tabular}

OTT: oral transit time; PTT: pharyngeal transit time; PC: pharyngeal clearance; UESO: upper esophageal sphincter opening; HM: hyoid movement; OPTT: oral-pharyngeal transit time; $\mathrm{Cl}$ : confidence interval.

OTT, PTT and OPTT with height. Result of the correlation of height with PTT is presented in Figure 2.

\section{Discussion}

In the present investigation, we evaluated the influence of body height on oral-pharyngeal transit after the swallowing of $10 \mathrm{~mL}$ liquid bolus in healthy men and women. There was no significant difference in the duration of oral and pharyngeal phases of swallowing between tall and short individuals if we consider men and women together. However, women have a positive correlation of OTT, PTT, OPTT and height. A longer pharyngeal phase of swallowing (PTT and PC) was seen in men compared with women, which may suggest an effect of sex on pharyngeal transit; nevertheless, the group of men was also taller than the group of women strongly suggesting an influence of height in these parameters.

These findings are in contradiction with previous results showing no difference between men and women in pharyn-

Table 2. Oral and Pharyngeal Bolus Transit Duration (Milliseconds) in Shorter (Mean Height: $1.66 \mathrm{~m}, \mathrm{~N}=10$ ) and Taller (Mean Height: $1.87 \mathrm{~m}, \mathrm{~N}=10$ ) Men, After Swallows of $10 \mathrm{~mL}$ Liquid Barium Bolus

\begin{tabular}{llllllll} 
& \multicolumn{2}{c}{ Shorter } & & \multicolumn{2}{c}{ Taller } \\
\cline { 2 - 3 } & Mean & $\mathbf{9 5 \%}$ CI & & Mean & $\mathbf{9 5 \%}$ CI & P value \\
\hline OTT & 753 & $646-859$ & & 592 & $456-727$ & 0.03 \\
PTT & 336 & $296-376$ & & 400 & $197-503$ & 0.21 \\
PC & 625 & $559-691$ & & 617 & $500-735$ & 0.33 \\
UESO & 395 & $358-431$ & & 387 & $333-441$ & 0.71 \\
HM & 912 & $729-1,094$ & 875 & $776-974$ & 0.77 \\
OPTT & 1,083 & $962-1,204$ & 1,001 & $843-1,159$ & 0.58 \\
\hline
\end{tabular}

OTT: oral transit time; PTT: pharyngeal transit time; PC: pharyngeal clearance; UESO: upper esophageal sphincter opening; HM: hyoid movement; OPTT: oral-pharyngeal transit time; $\mathrm{Cl}$ : confidence interval.
Table 3. Oral and Pharyngeal Bolus Transit Duration (Milliseconds) in Shorter (Mean Height: $1.57 \mathrm{~m}, \mathrm{~N}=10$ ) and Taller (Mean Height: $1.74 \mathrm{~m}, \mathrm{~N}=10$ ) Women, After Swallows of 10 $\mathrm{mL}$ Liquid Barium Bolus

\begin{tabular}{lllllll} 
& \multicolumn{2}{c}{ Shorter } & & \multicolumn{2}{c}{ Taller } & P value \\
\cline { 2 - 3 } \cline { 6 - 7 } & Mean & $\mathbf{9 5 \%}$ CI & & Mean & $\mathbf{9 5 \%}$ CI & \\
\hline OTT & 678 & $570-787$ & & 1,122 & $949-1,296$ & 0.04 \\
PTT & 217 & $192-242$ & & 259 & $232-287$ & 0.11 \\
PC & 419 & $377-461$ & 510 & $468-553$ & 0.02 \\
UESO & 296 & $274-318$ & 338 & $311-366$ & 0.12 \\
HM & 794 & $693-895$ & 930 & $792-1,067$ & 0.05 \\
OPTT & 965 & $793-1,137$ & 1,338 & $1,138-1,538$ & 0.04 \\
\hline
\end{tabular}

OTT: oral transit time; PTT: pharyngeal transit time; PC: pharyngeal clearance; UESO: upper esophageal sphincter opening; HM: hyoid movement; OPTT: oral-pharyngeal transit time; $\mathrm{Cl}$ : confidence interval.

geal transit duration with swallows of a $10 \mathrm{~mL}$ liquid bolus [17]. In the study by Molfender and Steele [11], no differences was found between men (mean height of $179 \mathrm{~cm}$ ) and women (mean height of $161 \mathrm{~cm}$ ) in PTT, and no correlation was found between height and PTT, indicating that neither sex nor height has influence on PTT. However, a small number of individuals were included in their investigation (10 men and 10 women) [11]. Altogether, these findings suggest that body height is not a determinant of PTT, but individuals with higher height tend to have longer PTT than shorter individuals.

Anatomic and functional differences in mouth and pharynx were seen between men and women, which may be explained by differences in their height. Men can take a larger volume of liquid into the mouth than women [28], due to higher anthropometric orofacial measures [28, 29]. When measured in the sitting position, pharyngeal cross-sectional area is greater in men than in women [24]. We hypothesize that these anatomic differences may be related to height differences between men and women, but specific investigations are needed

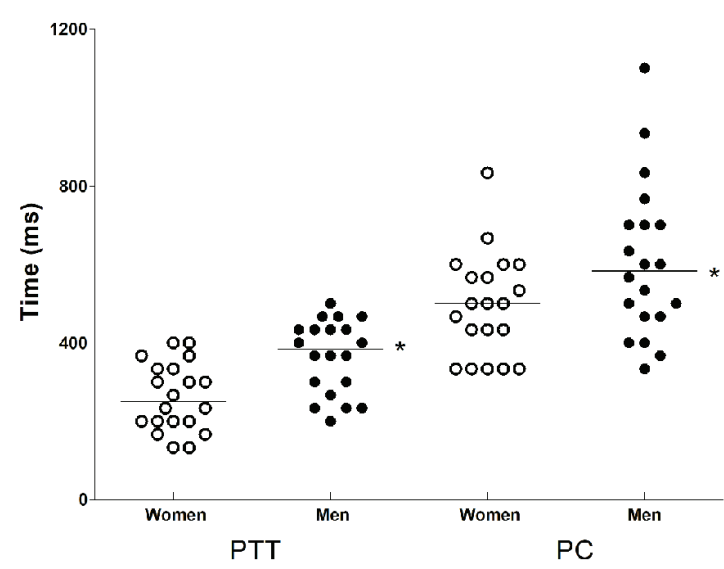

Figure 1. Pharyngeal transit time (PTT) and pharyngeal clearance $(\mathrm{PC})$ in women (mean height: $166 \mathrm{~cm}$ ) and men (mean height: 177 $\mathrm{cm}$ ) after swallows of $10 \mathrm{~mL}$ liquid bolus. Horizontal bars represent the mean. ${ }^{*} P=0.02$ vs. women. 
Table 4. Spearman's Correlation Coefficient ( $r$ ) Between Height and Swallowing Duration in Men $(N=20)$ and Women $(\mathrm{N}=20)$ With Swallowing of $10 \mathrm{~mL}$ Liquid Bolus

\begin{tabular}{|c|c|c|c|c|c|c|}
\hline & \multicolumn{2}{|c|}{ Men } & \multicolumn{2}{|c|}{ Women } & \multicolumn{2}{|c|}{ All } \\
\hline & $\mathbf{r}$ & P value & $\mathbf{r}$ & P value & $\mathbf{r}$ & $P$ value \\
\hline OTT & -0.22 & 0.35 & 0.63 & 0.01 & 0.07 & 0.68 \\
\hline PTT & -0.05 & 0.84 & 0.45 & 0.04 & 0.40 & 0.01 \\
\hline $\mathrm{PC}$ & -0.36 & 0.12 & 0.13 & 0.58 & 0.07 & 0.68 \\
\hline UESO & -0.16 & 0.49 & 0.38 & 0.10 & 0.19 & 0.25 \\
\hline HM & -0.10 & 0.68 & 0.37 & 0.10 & 0.22 & 0.17 \\
\hline OPTT & 0.11 & 0.66 & 0.69 & 0.01 & 0.22 & 0.16 \\
\hline
\end{tabular}

OTT: oral transit time; PTT: pharyngeal transit time; PC: pharyngeal clearance; UESO: upper esophageal sphincter opening; HM: hyoid movement; OPTT: oral-pharyngeal transit time.

to confirm it. Also, it is worth pointing out that oropharyngeal, laryngeal and hypopharyngeal volumes, as well as pharyngeal length and width have a positive correlation with body height [23]. A recent publication described that in the population over the age of 65 years, men with a height of $171.5(8.0) \mathrm{cm}$ have a larger pharyngeal volume of $39.5(9.4) \mathrm{cm}^{3}$ than women with a height of $158.8(7.5) \mathrm{cm}$ who have a pharyngeal volume of $30.0(6.7) \mathrm{cm}^{3}(\mathrm{P}<0.05)$. This difference in pharyngeal volume has influence on pharyngeal function [30].

However, in our population, possible differences between short and tall individuals are small, and there were also overlapping results in the two groups, which indicate that the influence of height on PTT may not have clinical relevance in healthy individuals. Nevertheless, in patients with dysphagia, understanding the influence of height on temporal parameters of swallowing could be relevant to rehabilitation, which is still an open field of investigation. Longer pharyngeal transit may require a longer time to ingest a meal, and hence the swallowing of smaller volumes.

There is a high variability in swallowing measures described in the literature [31]. Such variability may be due to variation within and between subjects, as well as to lack of standardized definitions of measures. The concept of PC used in this investigation, for example, was reported as PTT in other publication [31]. The use of different names for the same measurement may be a source of confusion in the videofluoroscopic evaluation of swallowing in patients with dysphagia. Therefore, precise definitions of each measurement would allow clear comparisons between groups, bolus viscosity and bolus volume.

This study has some limitations. First, a larger number of volunteers would help to clarify whether body height influences swallowing duration, mainly PTT and PC. Second, evaluation of oral and pharyngeal transit of a paste bolus might yield differences not seen with a liquid bolus; for example, an increase in the viscosity of the barium preparation causes an increase in PTT and PC $[12,32]$. Third, due to methodological limitations related to the duration of radiological examination, we were not able to evaluate the influence of height on the esophageal phase of swallowing. Finally, although tall subjects

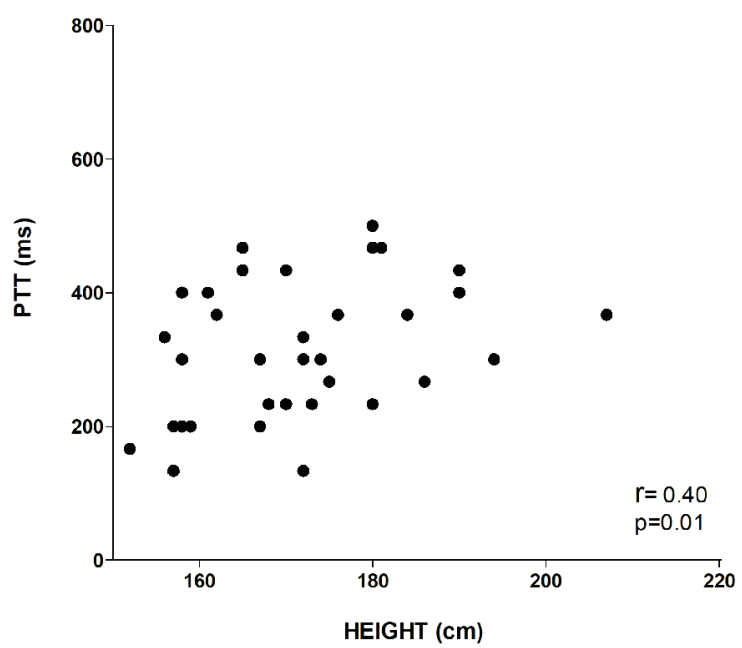

Figure 2. Correlation of height with pharyngeal transit time (PTT) of the individuals included in the investigation $(N=40)$.

were younger than shorter subjects, this difference probably had no influence on the results, since the effect of age on swallowing is more relevant in individuals older than 60 years [19, $33,34]$.

In conclusion, in women oral and pharyngeal transit time of a $10 \mathrm{~mL}$ liquid bolus was influenced by height and was longer in taller subjects.

\section{Conflict of Interest}

The authors declare no conflict of interest.

\section{Author Contributions}

The authors Marcia RKB Regueiro, Luana C Parreira, Weslania V Nascimento and Roberto O Dantas participated in the design of the study, in data acquisition and interpretation, drafted the initial manuscript and approved the final manuscript as submitted.

\section{Financial Support}

This research received no specific grant from any agency, and no financial support for the research, authorship and/or publication of this article.

\section{References}

1. Shaw SM, Martino R. The normal swallow: muscular and neurophysiological control. Otolaryngol Clin North Am. 2013;46(6):937-956.

2. Matsuo K, Palmer JB. Coordination of oro-pharyngeal food transport during chewing and respiratory phase. 
Physiol Behav. 2015;142:52-56.

3. Clave P, Shaker R. Dysphagia: current reality and scope of the problem. Nat Rev Gastroenterol Hepatol. 2015;12(5):259-270.

4. Jones B, Donner MW, Rubesin SE, Ravich WJ, Hendrix TR. Pharyngeal findings in 21 patients with achalasia of the esophagus. Dysphagia. 1987;2(2):87-92.

5. dos Santos CM, Cassiani RA, Dantas RO. Videofluoroscopic evaluation of swallowing in Chagas' disease. Dysphagia. 2011;26(4):361-365.

6. Triadafilopoulos G, Hallstone A, Nelson-Abbott H, Bedinger K. Oropharyngeal and esophageal interrelationships in patients with nonobstructive dysphagia. Dig Dis Sci. 1992;37(4):551-557.

7. Cassiani RA, Mota GA, Dantas RO. Oral and pharyngeal bolus transit in gastroesophageal reflux disease. Esophagus. 2015;12(4):345-351.

8. de Deus Chaves R, Chiarion Sassi F, Davison Mangilli L, Jayanthi SK, Cukier A, Zilberstein B, Furquim de Andrade CR. Swallowing transit times and valleculae residue in stable chronic obstructive pulmonary disease. BMC Pulm Med. 2014;14:62.

9. Cassiani RA, Santos CM, Baddini-Martinez J, Dantas RO. Oral and pharyngeal bolus transit in patients with chronic obstructive pulmonary disease. Int J Chron Obstruct Pulmon Dis. 2015;10:489-496.

10. Mendell DA, Logemann JA. Temporal sequence of swallow events during the oropharyngeal swallow. J Speech Lang Hear Res. 2007;50(5):1256-1271.

11. Molfenter SM, Steele CM. Variation in temporal measures of swallowing: sex and volume effects. Dysphagia. 2013;28(2):226-233.

12. Nascimento WV, Cassiani RA, Santos CM, Dantas RO. Effect of bolus volume and consistency on swallowing events duration in healthy subjects. J Neurogastroenterol Motil. 2015;21(1):78-82.

13. Perlman AL, Schultz JG, VanDaele DJ. Effects of age, gender, bolus volume, and bolus viscosity on oropharyngeal pressure during swallowing. J Appl Physiol (1985). 1993;75(1):33-37.

14. Watts CR, Kelly B. The Effect of Bolus Consistency and Sex on Electrophysiological Measures of Hyolaryngeal Muscle Activity During Swallowing. Dysphagia. 2015;30(5):551-557.

15. Hughes TA, Wiles CM. Clinical measurement of swallowing in health and in neurogenic dysphagia. QJM. 1996;89(2):109-116.

16. Alves LM, Cassiani Rde A, Santos CM, Dantas RO. Gender effect on the clinical measurement of swallowing. Arq Gastroenterol. 2007;44(3):227-229.

17. Dantas RO, de Aguiar Cassiani R, dos Santos CM, Gonzaga GC, Alves LM, Mazin SC. Effect of gender on swallow event duration assessed by videofluoroscopy. Dysphagia. 2009;24(3):280-284.

18. Hughes TA, Liu P, Griffiths H, Wiles CM. The repeatability and variability of electrical impedance tomography indices of pharyngeal transit time in normal adults. Physiol
Meas. 1995;16(3 Suppl A):A79-86.

19. Robbins J, Hamilton JW, Lof GL, Kempster GB. Oropharyngeal swallowing in normal adults of different ages. Gastroenterology. 1992;103(3):823-829.

20. Kim Y, McCullough GH, Asp CW. Temporal measurements of pharyngeal swallowing in normal populations. Dysphagia. 2005;20(4):290-296.

21. Molfenter SM, Steele CM. Use of an anatomical scalar to control for sex-based size differences in measures of hyoid excursion during swallowing. J Speech Lang Hear Res. 2014;57(3):768-778.

22. Inamoto Y, Saitoh E, Okada S, Kagaya H, Shibata S, Baba M, Onogi K, et al. Anatomy of the larynx and pharynx: effects of age, gender and height revealed by multidetector computed tomography. J Oral Rehabil. 2015;42(9):670677.

23. Daniel MM, Lorenzi MC, da Costa Leite C, Lorenzi-Filho G. Pharyngeal dimensions in healthy men and women. Clinics (Sao Paulo). 2007;62(1):5-10.

24. Huang J, Shen H, Takahashi M, Fukunaga T, Toga H, Takahashi K, Ohya N. Pharyngeal cross-sectional area and pharyngeal compliance in normal males and females. Respiration. 1998;65(6):458-468.

25. Regueiro M, Nascimento WV, Parreira LC, Dantas RO. Videofluoroscopic analysis of different volumes of liquid bolus swallowing in healthy individuals: comparison between height and sex. Clinics (Sao Paulo). 2017;72(11):693-697.

26. Cichero JA, Lam P, Steele CM, Hanson B, Chen J, Dantas RO, Duivestein J, et al. Development of international terminology and definitions for texture-modified foods and thickened fluids used in dysphagia management: the IDDSI framework. Dysphagia. 2017;32(2):293-314.

27. Schall R. Estimation in generalized linear models with random effects. Biometrika. 1991;78(4):719-727.

28. Nascimento WV, Cassiani RA, Dantas RO. Gender effect on oral volume capacity. Dysphagia. 2012;27(3):384389.

29. Nascimento WV, Cassiani Rde A, Dantas RO. Effect of gender, height and race on orofacial measurements. CoDAS. 2013;25(2):149-153.

30. Molfenter SM, Lenell C, Lazarus CL. Volumetric changes to the pharynx in healthy aging: consequence for pharyngeal swallow mechanics and function. Dysphagia. 2018.

31. Molfenter SM, Steele CM. Temporal variability in the deglutition literature. Dysphagia. 2012;27(2):162-177.

32. Stokely SL, Molfenter SM, Steele CM. Effects of barium concentration on oropharyngeal swallow timing measures. Dysphagia. 2014;29(1):78-82.

33. Humbert IA, Fitzgerald ME, McLaren DG, Johnson S, Porcaro E, Kosmatka K, Hind J, et al. Neurophysiology of swallowing: effects of age and bolus type. Neuroimage. 2009;44(3):982-991.

34. de Lima Alvarenga EH, Dall'Oglio GP, Murano EZ, Abrahao M. Continuum theory: presbyphagia to dysphagia? Functional assessment of swallowing in the elderly. Eur Arch Otorhinolaryngol. 2018;275(2):443-449. 